\title{
ECLETICA
}

www.scielo.br/eq

Volume 30, número 4, 2005

\section{Determinação de cádmio em amostras de urina e soro humano por espectrometria de absorção atômica em forno de grafite usando irídio como modificador permanente}

\author{
F. G. Pinto, U. V. Rey, L. M. S. Ansaloni, D. Andrada, J. B. B. Silva* \\ Departamento de Química, Universidade Federal de Minas Gerais, \\ Avenida Antônio Carlos 6627, 31270-901 Belo Horizonte, MG, Brazil. \\ *E-mail: bentojb@terra.com.br
}

\begin{abstract}
Resumo: No presente estudo, foram investigadas diferentes substâncias para atuarem como modificadores químicos na determinação direta de cádmio em soro e urina humanos sem digestão prévia das amostras. A preparação da amostra foi feita diretamente nos copos do amostrador automático por diluição 1+4 de soro e $1+1$ de urina com ácido nítrico $1 \% \mathrm{v} / \mathrm{v}$ contendo $0.02 \% \mathrm{v} / \mathrm{v}$ de cloreto de tricetil metil amônio (CTAC). Foram investigadas as melhores condições de determinação por meio de curvas de temperatura de pirólise e atomização na presença da matriz e do analito levando-se em conta a forma do pulso de absorção, baixas temperaturas na atomização, fundo corrigido e sensibilidade. Foram efetuados estudos na ausência de modificador e com a mistura universal em solução de Pd e Mg ( 10 e $15 \mu$ g, respectivamente) e com rutênio $(500 \mu \mathrm{g})$ e irídio $(500 \mu \mathrm{g})$ como modificadores permanentes. Para Ir permanente, as massas características foram $0.8 \mathrm{pg}$ para soro e $0.7 \mathrm{pg}$ para urina (recomendado de $2 \mathrm{pg}$ ). Na investigação do uso de Ir permanente, foi observado que o pico foi simétrico, retornando à linha de base em $3 \mathrm{~s}$ e com fundo corrigido completamente com valores ótimos por pirólises e atomização de 300 e $1000^{\circ} \mathrm{C}$ para soro e 300 e $1100^{\circ} \mathrm{C}$ para urina. A calibração foi feita por ajuste de matriz e apresentou coeficiente de correlação de regressão linear típico de 0.999 . Análises de soro e urina fortificados mostraram recuperações que variaram entre 99.3 e 103.2 com um desvio padrão relativo (RSD, $n=3$ ) menor que $12 \%$ para soro e entre 93.1 e $102.2 \%$ com um RSD menor que $3 \%$ para urina. O limite de detecção $(\mathrm{k}=3, n=10)$ foi de 8 e 9 pg para soro e urina, respectivamente.
\end{abstract}

Palavras-chave: Espectrometria de absorção atômica com atomização eletrotérmica; cádmio; urina; soro; irídio permanente.

\section{Introdução}

Cádmio não apresenta função essencial ao organismo humano, animal, e ao metabolismo de plantas, sendo de grande interesse toxicológico porque é extremamente tóxico ao homem em baixas concentrações [1]. Este metal é um sub-produto da exploração do zinco e do chumbo, sendo esta uma importante fonte de contaminação ambiental por cádmio, há sérias restrições quanto a exploração destes metais em áreas próximas a grandes centros urbanos. [2,3]. Descoberto em 1817, cádmio vem sendo usado em escala industrial nos últimos 50 anos em uma variedade de aplicações como na indústria elétrica e galvânica devido a sua propriedade não corrosiva, na produção de cloreto de polivinila (PVC) como estabilizante, nas indústrias de plástico e vidro como pigmento, e na indústria de baterias de $\mathrm{Ni}-\mathrm{Cd}$ como material de cátodo, além de fazer parte de várias ligas metálicas [4]. Entretanto somente uma parte da quantidade total de cádmio ingerida é retida no corpo humano, acumulando-se no fígado e nos tecidos dos rins com um tempo de meia-vida estimado de 20 a 30 anos [5]. A Agência Internacional de Pesquisa 
sobre o Câncer (IARC) considera que há evidências suficientes para classificar o cádmio como agente carcinogênico, embora alguns fatores precisam ser considerados nesta avaliação, como escassez de dados históricos, número limitado de trabalhos, tabagismo, e associação com outros elementos (níquel, arsênio). [6].

Há várias metodologias encontradas na literatura para a determinação de cádmio em urina e outros fluidos biológicos. Onar e Temizer [7] propuseram um método para determinar $\mathrm{Cd}$ e $\mathrm{Pb}$ em urina usando a voltametria de redissolução anódica com pulso diferencial (DP-ASV). Um método para determinação simultânea de $\mathrm{Zn}, \mathrm{Cd}, \mathrm{Pb}$, e $\mathrm{Cu}$ em urina de pacientes com a doença do pé-preto usando a voltametria de redissolução anódica foi descrito [8], enquanto que em outro estudo, DPASV foi usada para a simultânea determinação de concentrações urinárias de $\mathrm{Zn}, \mathrm{Cd}, \mathrm{Pb}$ e $\mathrm{Cu}$ em trabalhadores de uma indústria da produção de aço [9].

Vários métodos para a determinação de cádmio têm sido desenvolvidos usando a espectrometria de absorção atômica em forno de grafite (ET AAS). Lund e Larsen propuseram um método para a determinação de cádmio em urina por ET AAS, em que o metal é eletrolizado para dentro de um fio de platina[10].

Microdeterminação de chumbo e cádmio em sangue e urina por ET AAS foi feita usando extração por metil isobutil cetona após quelação por pirrol ditiocarbamato de amônio [11]. Slavin e colaboradores [12] usando ET AAS determinaram $\mathrm{Cd}$ em urina usando $\left(\mathrm{NH}_{4}\right)_{2} \mathrm{HPO}_{4}$ e $\mathrm{HNO}_{3}$ como modificadores químicos com um limite de detecção de $0,4 \mu \mathrm{L}^{-1}$, enquanto o limite encontrado por De Broe et al. [13] com plataforma de L'Vov tratada com molibdato de amônio e calibração por ajuste de matriz foi de $0,4 \mu \mathrm{L}^{-1}$. Na determinação de $\mathrm{Cd}$ em sangue e soro, amostras foram diluídas por adição de $0,015 \%$ (w/v) de Triton X-100 e 0,1 \% (w/ v) de dihidrogenofosfato de amônio, que foram introduzidos diretamente dentro do tubo de grafite. Uma solução contendo $15 \%$ (w/v) de peróxido de hidrogênio e $0,65 \%(\mathrm{~W} / \mathrm{V})$ de ácido nítrico foi também introduzida no atomizador eletrotérmico separadamente [14]. Uma alternativa interessante e bastante explorada nos últimos anos para determinação de metais por ET AAS é o uso de modificadores permanentes para promover aumento de sensibilidade na análise e eliminação quase que completa dos possíveis constituintes concomitantes da matriz por possibilitar a aplicação de maiores temperaturas de pirólise sem perdas do analito [15].

O presente trabalho investiga o desempenho de diferentes substâncias químicas como modificadores químicos na determinação direta de cádmio em urina e soro humano por espectrometria de absorção atômica com atomização eletrotérmica sem a necessidade de digestão prévia da amostra

\begin{tabular}{ccccc}
\hline Etapa & Temperatura $/{ }^{\circ} \mathrm{C}$ & Rampa/s & Permanência/s & $\begin{array}{c}\text { Vazão de Argônio } \\
\mathrm{mL} \mathrm{min}^{-1}\end{array}$ \\
\hline 1 & 90 & 5 & 10 & 250 \\
2 & 140 & 5 & 10 & 250 \\
3 & 300 & 10 & 20 & 250 \\
$4^{*}$ & $1000^{\mathrm{a}, \mathrm{b}}$ & 0 & 5 & 0 \\
5 & 2500 & 1 & 5 & 250 \\
6 & 20 & 1 & 5 & 250 \\
\hline
\end{tabular}

* leitura nesta etapa; $\mathrm{a}=$ urina, $\mathrm{b}=$ soro humano.

Tabela 1. Programa de aquecimento para determinação de $\mathrm{Cd}$ em urina humana por ET AAS usando Ir como modificador permanente. 


\section{Materiais e métodos}

\section{Instrumentação}

Todas as medidas foram feitas em um espectrômetro de absorção atômica Hitachi Z-8200 (Mitorika, Ibaraki, Japão), equipado com forno de grafite e um amostrador automático SSC-300 (Hitachi) e com correção de fundo por Efeito Zeeman. Absorvância integrada (área de pico) foi usada para avaliação do sinal. Lâmpada de cátodo oco da Hitachi (No. 139-3564) foi operada com corrente de 7,5 mA e a largura de fenda foi de 1,3 $\mathrm{nm}$. O comprimento de onda usado foi de $228,8 \mathrm{~nm}$. O volume pipetado para dentro do tubo de grafite foi de $20 \mu \mathrm{L}$ tanto para a amostra diluída quanto para as soluções de calibração. O volume de modificador químico quando usado em solução foi de $10 \mu \mathrm{L}$. Argônio, 99,996 \% (White Martins, Belo Horizonte, MG, Brazil), foi usado como gás de purga. Tubos de grafite com recobrimento pirolítico sem plataforma (Hitachi, Part No. 190-6003) foram usados em todos os estudos. Nos estudos usando modificador permanente, os tubos foram tratados com métodos descritos anteriormente para Ir e Rh [15], ou para $\mathrm{Ru}$ [16]. O programa de aquecimento do forno de grafite para a determinação de $\mathrm{Cd}$ em urina e soro foi otimizado e está mostrado na Tabela

1.

\begin{tabular}{|c|c|c|c|}
\hline Modificador & Tp (temp pirólise) & Ta (temp. atomização) & Massa característica, pg \\
\hline \multicolumn{4}{|c|}{ Urina } \\
\hline Sem & 600 & 1500 & 9,8 \\
\hline $\mathrm{Pd}+\mathrm{Mg}$ & 400 & 1000 & 0,9 \\
\hline $\mathrm{Ru}$ & 300 & 1000 & 0,8 \\
\hline Ir & 300 & 1000 & 0,7 \\
\hline \multicolumn{4}{|c|}{ Soro } \\
\hline Sem & 300 & 1000 & 3,9 \\
\hline $\mathrm{Pd}+\mathrm{Mg}$ & 300 & 1100 & 1,0 \\
\hline $\mathrm{Ru}$ & 300 & 1000 & $*$ \\
\hline Ir & 300 & 1000 & 0,8 \\
\hline
\end{tabular}

* praticamente não fornece nenhum sinal analítico em toda a faixa de atomização estudada

Tabela 2. Características dos modificadores testados na determinação de $\mathrm{Cd}$ em soro e urina.
Todos os reagentes usados foram de alto grau analítico. Aágua foi deionizada em um sistema MilliQ (Millipore, Bedford, MA, USA). O ácido nítrico foi da Merck (Darmstadt, Germany), No. 7587956. As seguintes soluções estoque de $1000 \mu \mathrm{g} \mathrm{mL}^{-1}$ foram usadas: rutênio (Fluka, Buchs, Switzerland, No. 84033) e irídio (Fluka, No. 58195), todas em $1 \mathrm{~mol} \mathrm{~L}^{-1}$ de ácido clorídrico; soluções de nitrato de magnésio (Merck, No. B593213 431) e de nitrato de paládio (Merck, No. B936989 710). Soluções padrões de cádmio foram preparadas a partir de uma solução estoque de $1000 \mathrm{mg} \mathrm{L}^{-1}$ da Merck feita por diluição de uma ampola de Titrisol em ácido nítrico $3 \%$ v/v.

\section{Procedimento}

Amostras de urina foram diluídas $1+1 \mathrm{e}$ as de soro $1+4$ com ácido nítrico $1 \% \mathrm{v} / \mathrm{v}$ contendo $0,02 \% \mathrm{v} / \mathrm{v}$ de cloreto de tricetil metil amônio $(C T A C)$. O CTAC é um surfactante que age como um diluente ajudando na extração do metal e também como um detergente para eliminação/limpeza de resíduos carbonáceos formados dentro do tubo de grafite, além de auxiliar a limpeza do capilar do amostrador 
automático entre as medidas. A calibração foi feita a partir de soluções previamente preparadas contendo $500 \mu \mathrm{L}$ de urina ou $200 \mu \mathrm{L}$ de soro em um volume total de $1000 \mu \mathrm{L}$ com quantidades crescentes de $\mathrm{Cd}$. A faixa de calibração foi de 0,1-10 e de 0,1-15 $\mu \mathrm{g} \mathrm{L}^{-1}$ urina e soro, respectivamente.

Para verificação da exatidão das metodologias propostas, foram efetuados estudos de recuperação de amostras de urina e de soro. $\mathrm{O}$ limite de detecção (LOD, $\mu \mathrm{g} \mathrm{L}^{-1}$ ) foi calculado usando a equação LOD $=3 \times \mathrm{S}_{\mathrm{BL}} / \mathrm{b}$, onde $\mathrm{S}_{\mathrm{BL}}$ é o desvio padrão de 10 medidas do branco (ácido nítrico $1 \% \mathrm{v} / \mathrm{v}$, com $0,02 \%$ v/v de $C T A C$ ) e b é a inclinação da curva de calibração.

\section{Resultados e discussão}

\section{Curvas de temperaturas de pirólise e de atomização}

Para efeito de comparação do comportamento térmico de cádmio submetido a um programa de aquecimento de forno em cada uma das superfícies testadas foram obtidas curvas de temperatura de pirólise e de atomização para $\mathrm{Cd}$ na presença da urina ou do soro. Foram comparadas as determinações sem o uso de modificador, com a mistura de $\mathrm{Pd}+\mathrm{Mg}$ (modificador universal), além de $\mathrm{Ru}$ e $\mathrm{Ir}(500 \mu \mathrm{g}$ de cada) como modificadores permanentes. A Tabela 2 resume as principais temperaturas otmizadas com suas respectivas sensibilidades para cada modificador testado para urina e soro humanos.

Inicialmente foi estudada a determinação de Cd em urina diluída $1+1 \mathrm{em}$ ácido nítrico $1 \% \mathrm{v} / \mathrm{v}$ contendo $0,02 \%$ v/v de CTAC contaminada com 10 $\mu \mathrm{g} \mathrm{L}^{-1}$ de $\mathrm{Cd}$ sem o uso de modificador químico. Neste estudo, para toda a faixa de temperatura estudada os valores de absorvância integrada de $\mathrm{Cd}$ foram muito baixos. Com o uso da mistura de $\mathrm{Pd}+\mathrm{Mg}$, as melhores temperatures de pirólise e atomização foram de 400 e $1000^{\circ} \mathrm{C}$, entretanto a sensibilidade foi claramente menor $(\sim 0,5 \mathrm{Abs}, \mathrm{s})$ quando comparada com aos resultados que foram obtidos para Ir permanente ( 0,7 Abs,s), que foi a melhor opção. Com o uso de Ir como modificador permanente, as melhores temperatures de pirólise e atomização foram consideravelmente baixas (300 e $1000{ }^{\circ} \mathrm{C}$ ), e a sensibilidade obtida foi a mais alta (massa característica $\mathrm{m}_{\mathrm{o}}$ de $0,7 \mathrm{pg}$, sendo que a recomendada pelo fabricante do equipamento em solução aquosa sem o uso de modificador é de 2,0 pg). Nestas condições o pico de absorção foi simétrico, retornando a linha base em $3 \mathrm{~s}$, com fundo baixo e corrigido (cerca de 0,3 Abs, s).

Para o desenvolvimento da metodologia para determinação de $\mathrm{Cd}$ em soro, a melhor diluição obtida foi $1+4 \mathrm{em}$ ácido nítrico $1 \% \mathrm{v} / \mathrm{v}$ contendo $0,02 \%$ v/v de CTAC sendo amostra de soro contaminada com $10 \mu \mathrm{g} \mathrm{L}^{-1} \mathrm{de} \mathrm{Cd}$. Aqui como na urina o uso de irídio permanente mostrou-se ser a melhor opção apresentando maior sensibilidade em relação ao não uso de modificador e aos outros modificadores testados, com pulsos de absorção simétricos retornando a linha base em $3 \mathrm{~s}$ com fundo baixo e corrigido ( $0.35 \mathrm{Abs}, \mathrm{s})$. As temperaturas ótimas de pirólise e atomização foram de $300 \mathrm{e}$ $1000^{\circ} \mathrm{C}\left(\mathrm{m}_{\mathrm{o}} \mathrm{de} 0,8 \mathrm{pg}\right)$.

Para ambos os casos urina e soro, nas temperaturas otimizadas a absorção de fundo foi plenamente corrigida ( 0,3 Abs,s).

\section{Figuras analíticas de mérito}

Obtido o programa de forno para Ir permanente (Tabela 1), foram feitas curvas de calibração usando o método de ajuste de matriz. Analisando a Tabela 3 foi observado que a curva de calibração para urina apresentou um satisfatório coeficiente de correlação linear $\left(\mathrm{r}^{2}\right)$, uma massa característica quase três vezes melhor que a recomendada para soluções aquosas e limite de detecção compatível com alguns resultados da literatura. As figuras analíticas de mérito para soro estão também mostradas na Tabela 3. A curva de calibração apresentou bom coeficiente de correlação linear e o limite de detecção foi baixo. Foi verificado que os estudos de recuperações para as duas matrizes (urina e soro) investigados neste trabalho em todos os níveis de Cd estão sempre próximos de $100 \%$, indicando uma aceitável exatidão dos métodos propostos. Os desvios padrões encontrados foram comuns para análises usando o forno de grafite (Tabela 4). 


\begin{tabular}{|c|c|c|c|c|c|c|}
\hline Amostra & $\begin{array}{l}\text { LOD, } \\
\mu \mathrm{g} / \mathrm{L}\end{array}$ & $\begin{array}{c}\mathrm{M}_{\mathrm{o}}, \mathrm{pg} \\
\text { (recomendada) }\end{array}$ & $\mathrm{RSD}, \mathrm{n}=3$ & $\mathrm{r}^{2}$ & $\begin{array}{c}\text { Calibração, } \\
\mu \mathrm{g} / \mathrm{L}\end{array}$ & $\begin{array}{c}\text { Valor } \\
\text { limite, } \\
\mu \mathrm{g} / \mathrm{dL}[17]\end{array}$ \\
\hline Urina & 0,45 & $0,7(2,0)$ & $<3$ & 0,99203 & $0,1-10.0$ & 5,0 \\
\hline Soro & 0,40 & $0,8(2,0)$ & $<9$ & 0,99203 & $0,1-15.0$ & 5,0 \\
\hline
\end{tabular}

Tabela 3. Características analíticas obtidas para a determinação de cádmio em amostras urina humana e soro por ET AAS usando $500 \mathrm{mg}$ de irídio.

\begin{tabular}{|c|c|c|}
\hline $\begin{array}{l}\text { Concentração } \\
\text { esperada }\left(\mu \mathrm{g} \mathrm{L}^{-1}\right)\end{array}$ & $\begin{array}{l}\text { Concentração } \\
\text { determinada }\left(\mu \mathrm{g} \mathrm{L}^{-1}\right)\end{array}$ & $\% \operatorname{RSD}(\mathrm{n}=3)$ \\
\hline \multicolumn{3}{|c|}{ Urina } \\
\hline 1,50 & 1,52 & 1,63 \\
\hline 2,0 & 2,49 & 2,76 \\
\hline 3,50 & 3,26 & 1,24 \\
\hline 4,50 & 4,60 & 0,18 \\
\hline 5,50 & 5,57 & 0,14 \\
\hline 6,50 & 6,11 & 1,63 \\
\hline 7,50 & 7,31 & 1,23 \\
\hline 8,50 & 8,21 & 0,10 \\
\hline 9,50 & 9,46 & 1,60 \\
\hline \multicolumn{3}{|c|}{ Soro } \\
\hline 1,50 & 1,42 & 5,80 \\
\hline 3,00 & 2,98 & 6,20 \\
\hline 4,50 & 4,65 & 2,80 \\
\hline 6,00 & 6,18 & 4,20 \\
\hline, 50 & 6,95 & 6,30 \\
\hline 9,00 & 9,20 & 3,10 \\
\hline 12,00 & 12,80 & 8,20 \\
\hline
\end{tabular}

Tabela 4. Recuperações de amostras de urina e soro contaminadas com Cd analisadas por ET AAS usando as metodologias propostas. 


\section{Conclusões}

Irídio revelou ser um promissor modificador permanente para a direta determinação de $\mathrm{Cd}$ em urina humana e soro sem necessidade de prévia digestão das amostras com somente uma diluição de $1+1$ para urina e $1+4$ para soro em ácido nítrico e CTAC. Boas sensibilidades foram obtidas para as duas matrizes com pulsos de absorção simétricos, fundos corrigidos e valores de recuperação dentro da faixa de valores normais em urina e soro, próximos em $100 \%$.

\section{Agradecimentos}

F. G. Pinto, U. V. Rey, D. Andrada e J. B. B. Silva agradecem pelas bolsas do CNPq. Os autores agradecem ao CNPq e à FAPEMIG pelo auxílio à pesquisa.

Recebido em: 08/08/2005

Aceito em: 09/11/2005

F. G. Pinto, U. V. Rey, L. M. S. Ansaloni, D. Andrada, J. B. B. Silva. Determination of cadmium in urine and human serum samples by electrothermal atomic absorption spectrometry using iridium as permanent modifier.

\begin{abstract}
In the present study, different substances were investigated as chemical modifiers in the direct determination of cadmium in human serum and urine without previous digestion of the samples. The preparation of the sample was made directly in autosampler cups by dilution $1+4$ of serum and $1+1$ of urine with nitric acid $1 \% \mathrm{v} / \mathrm{v}$ containing $0.02 \% \mathrm{v} / \mathrm{v}$ of cetiltrimethyl ammonium chloride. The optimum determination conditions through pyrolysis and atomization curves in the presence of the matrix and analyte taking into account the form of the absorption pulses, low atomization temperatures, background correction and sensitivity were investigated. Tests were carried out without chemical modifier, with the universal mixture of $\mathrm{Pd}$ and $\mathrm{Mg}(10$ and $15 \mu \mathrm{g}$, respectively), with ruthenium $(500 \mu \mathrm{g})$ and iridium $(500 \mu \mathrm{g})$ permanent modifiers. For permanent $\mathrm{Ir}$, the $\mathrm{m}_{\mathrm{o}}$ was $0.8 \mathrm{pg}$ for serum and $0.7 \mathrm{pg}$ for urine (recommended of $2 \mathrm{pg}$ ). Upon the investigation of the use of Ir permanent, it was observed that the peak was symmetrical, returned to the baseline in $3 \mathrm{~s}$ and that the background was fully corrected with optimum values for pyrolysis and atomization at 300 and $1000^{\circ} \mathrm{C}$ for serum and 300 and $1000^{\circ} \mathrm{C}$ for urine. Calibration was made by matrix matching method, and presented $\mathrm{r}^{2}$ (coefficient of correlation of linear regression) higher than 0.999. Analyses of spiked serum and urine samples yielded recoveries varying between 99.3 and 103.2 with a relative standard deviation $(\mathrm{RSD}, \mathrm{n}=3$ ) lower than $12 \%$ for serum and between 93.1 and $102.2 \%$ with an RSD lower than 3\% for urine. The detection limit $(\mathrm{k}=3, \mathrm{n}=10)$ were 8 and $9 \mathrm{pg}$ for serum and urine, respectively.
\end{abstract}

Keywords: electrothermal atomic absorption spectrometry; cadmium; serum; urine; permanent iridium.

\section{Referências}

[1] M.O. Amdur, J. C. D. Klaanen,; Casarett and Doll's Toxicology: the basic science of poison, Pergamon Press, New York, 4 ed. 1996.

[2] W. H. Porter, T. P. Moyer, Clinical toxicology IN: Burtis, C.A.; Ashwood, E.R. - Tietz textbook of clinical chemistry. W. B. Saunders Company, Philadelphia, 2th ed., 1994.

[3] L.Jarup, M.Berglund, , C. G. ElinderNordberg, M.Vather, J Work Environ Health, 24 (1998) 1.

[4] D. B. Tonks, A. J. Pesce, L. A. Kaplan, Cádmio In: Química Clínica: métodos. Panamericana, Buenos Aires, 1990.

[5] G. F. Nordberg, Effects and Dose-Response Relationships of Toxic Metals. Elsevier, New York, 1976.
[6] Z. A.Shaikh, J. B. Northup, P. Vestergaard, J. Toxicol. Environ. Health, 57(1999) 211.

[7] A. N. Onar, A. Temizer, Analyst, 112 (1987) 227.

[8] T. C. Pan, C. J. Horning, S. R. Lin, T. H. Lin, C. W. Huang, Biol. Trace Elem. Res. 38 (1993) 233.

[9] C. J. Horn, Analyst, 12 (1996) 1511.

[10] W. Lund, B. V. Larsen, Anal. Chim. Acta, (1996) 319.

[11] P.Allain, Y.Mauras, Clin. Chim. Acta, 91 (1979) 41.

[12] E. Pruszdowska, G. R. Carnick, W. Slavin, Clin. Chem. 29 (1983) 477.

[13] P. C. D'Haese, L. V. Lamberts, L. Liang, F. L. Van de Vyver, M. E. De Broe, Clin. Chem. 37 (1991) 1583.

[14] N. Campillo, P. Vinãs, I. Lopéz-García, M. HernándezCórdoba, Anal. Chim. Acta 390 (1999) 207.

[15] J. B. B. Silva, M. B. O. Giacomelli, I. G. Souza, A. J. 
Curtius, Microchem. J. 60 (1998) 249.

[16] J. B. B. Silva, M. A. M. Silva, A. J. Curtius, B. Welz, J. Anal. At. Spectrom. 14 (1999) 1737.
[17] Department of Health and Human Services (USA).Occupational Exposure to Cadmium. Final Rules. 1992, p. 1027. 